\title{
INFORMATION AS A STRATEGIC RESOURCE: A QUESTION OF COMMUNICATION
}

\author{
Johan Olaisen \\ Professor at the Norwegian School of Management, 1300 Sandvika, Norway \\ and at Bodø Graduate Business School, 8016 Mørkved, Norway
}

\section{INTRODUCTION}

It has been a momentos change. Information technology and information is no longer a business resource; it is the business environment. Increasingly, the right question to ask about information technology is not: "What can the machines do? but "What do we want them to do?". There has so far been three broad answers to that question. Each presents its own opportunities and creates its own problems. They are: Increase the Productivity and/or the Competitive advantage and/or the Responsiveness. Setting broad goals for the use of information technology has always been easier than reaching them. Part of the problem is the technology itself keeps moving the goal posts. Some of the biggest recent goal-post movements have been brought about by huge declines in the price of technology. The effect of this movement will be that the computers are going to work alongside humans - typically in three roles. As assistants, computers will do routine work, like preparing dossiers of information from databases. As advisers, the machines store and search huge quantities of information to provide facts and advice on everything from new products and services to the latest trade regulations. And as communicators, they spread information across companies and countries. It is as communicators the effect of computers will be felt most strongly over the next decade. This means easier access to any kind of internal and external information. This might as Strassmann (1985), Olaisen (1990) and Venkatraman (1989) have pointed out have a revolutionary effect on organizations. We might in the 90 s see a business-process redesign (communication enable things to be done in new and more efficient ways), business-network redesign (communication enable new network links), business-scope redesign (efficient customer communication enable some companies to move into new businesses).

We are in Scandinavia watching a growing awareness and consideration of 
the dependence of organizations upon their internal and external information systems. This new sensitivity to informational contributions to organizational success has pushed into prominence the concept of information resources management (IRM). IRM tries to link together managerial effectiveness and information acquisition and use. It is based on the premise that effective decisionmaking and strategic thinking cannot be divorced from information processing. The core task is information processing - moving information among individuals and groups to coordinate work. More and more of the Scandinavian companies are finding that this process needs another kind of management than their traditional information technology (IT) management.

IT-departments are therefore in more and more companies replaced by IRM-departments. Information itself is looked upon as the key resource for product development and product differentiation. Since information technology can be thought of as a resource that is fairly well defined and readily measurable - in terms of the number, memory capacity, transmission capacity, price, and so on, while information is a quite different resource that is less well understood and much more difficult to measure (Olaisen 1989), it appears to be necessary to make the distinction between information and information technology as clearly as possible to be able to develop usable frameworks. Information technology can be defined as the hardware and software that is used to collect, transmit, process and disseminate data (symbols) in an organization. Information might be defined as data that have been evaluated for some specific use. In most organizations there are a variety of evaluation filters for data. When it is acted upon the information it becomes knowledge in the individual, in the team and in the organization. Information is a resource just like capital, manpower, and equipment. As such information has value, (productivity, management support, and competitive value), costs money (to collect, store, process and disseminate), has qualities (timeliness, accuracy, form) and is controllable (can be accounted for and managed).

We want in this paper to give a state-of-the-art presentation of what we know about the management of information itself as a strategic resource. We will focus briefly on the background for the development from being mostly concerned about information technology to being concerned about both the technology itself and the communication possibilities given by the technology. We will include some of our own empirical findings on this issue from Norwegian banks, hotels and insurance companies. In short we attempt to consider some of the fundamental issues surrounding the notion of information as a strategic resource as well as report some empirical evidence as to what is actually being done among Norwegian companies in making these concepts operational. We will in the paper illustrate how information might be used a strategic resource in what we have labeled a dynamic learning organization.

We will at the end of the paper develop a model for the use of information as a strategic resource. 


\section{THE AWARENESS OF INFORMATION AND TOMORROWS CORPORATION}

What organizations actually do is often unreflective of their environment and often not the right thing at the right time (Laudon, 1985). Most organizations fail and very few of them live longer than a human lifetime (Starbuch 1983). This turbulence is illustrated by looking at how many of the companies on the Fortune 500 top list of 1979 who still operated independently in 1989 . Only $30 \%$ operated as they did in 1979 in 1989, 30\% have restructured operations and $40 \%$ are under new ownership (Olaisen 1990). Minzberg (1987:75) expressed it this way: "Most of the time they pursue a given strategic orientation. Change may seem continuous, but occurs in the context of that orientation ... and usually amounts to doing more of the same, perhaps better as well. Most organizations favour these periods of stability because they achieve success not by changing strategies but by exploiting the ones they have. They, like craftsmen, seek continuous improvement by using their distinctive competencies in established courses ... not intellectual knowledge, not analytical reports or abstracted facts and figures (though these can certainly help), but personal knowledge, intimate understanding, equivalent to the craftsmans feel for the clay".

The environmental turbulence has created a need for strategic information to be able to navigate a company. Management information systems and information resources management both reflect the information needs and attempts at establishing more comprehensive, and at the same time more precise, complex, integrated and discriminatory systems for providing managers with data and information needed for managing organizations in circumstances of change and turbulence.

The architecture of corporate organizations is in transition. Across the business landscape, companies are searching for new architecture that can serve them more effectively in a changing environment. This is done in an escalating pace of change with intensified competition, deregulated global markets, segmented markets and shifting customers preferences, diverse and transforming technology leading to greater flexibility and responsiveness and most of all as a part of this picture changing strategic alliances.

Large and complex organizations are particularly challenged:

Competition has forced them to find ways to lower costs of internal coordinating - in terms of both time and money.

- Demand for competitive innovations has caused them to look for ways to improve accountability and to empower teams at all levels.

a The global economy has pushed them to identify their true competitive advantage to find ways to achieve broad reach and scale without creating the "mass" this has traditionally required. 
Customer demand for quality has heightened the need to motivate employees with greater awareness of the meaning of their work.

As shown by Olaisen et al. (1990) the key to success in the airline industry is strategic alliances. The strategy of bridging companies to a world wide network of connected flights are followed by strategies for designing tunnels for the flow of information back to the individual company. The information systems are designed to give information that can be systematized to offer core services, facilitation services and supporting services according to the need of the different market segments. Together with excellence in the services the information systems and the flight "networking" can be seen as corners in a triangle that covers the strategic shape of the companies to come. In all corners there are ongoing battles each demanding alliances and joint ventures to succeed. Olaisen et al. (1990) found that the core task for Scandinavian Airline Systems (SAS) is information processing - moving information among individuals and groups in order to coordinate work. The basic structure for coordinating information processing traditionally has been hierarchy. Hierarchical organizations were built by grouping jobs/roles into work unit linking these via common reporting relationships and successive levels of management control. Perhaps the greatest single influence on organizational architecture has been the evolution of information technology. By providing alternatives to hiearchy, information technology is revolutionizing organizational design. Information systems, common architecture, shared databases, decision support tools, linked internal and external information sources - all create the capacity to coordinate behaviour without hierarchical control. Such technology and information allows the creation of autonomous work units, linked together via information. The great potential of information technology and information combined with the great demands of the ever-changing competitive environment - has led to innovations in information resources management.

Information management is the process of identifying, defining, collecting, storing, processing, protecting, and distributing information. It deals in information content, which is a business issue, that is understanding the need, use, and value of information in the organization (i.e. the flows of information). Another part of it addresses information content with software (data bases, information languages. software languages). Information technology is being decentralized through networks of microcomputers and communication networks, making integration difficult, but necessary.Large and complex organizations are more and more working in networks or intercompany systems. The processing of information to coordinate these systems is essential for intercompany systems.

The function of information management has grown from a physical control of paperwork to a main distributed resource for advice on all management levels and further on to become the key asset for the communication between suppliers, producers and customers. 


\title{
THE STRATEGIC ROLE OF INFORMATION SYSTEMS
}

\author{
The Theory Considerations Of Information \\ Versus Information Technology As A Strategic Resource
}

Lucas and Turner (1982) observed that information technology can be used to achieve strategic managerial objectives in three different ways: first, it can be used to obtain greater efficiencies in existing operations, secondly it can be used to improve the strategic planning process and thirdly it can be used to open new markets. Parson (1983) noted that if information technology was to become a feasible competitive weapon, the middle and the top managers would have to understand how its use affected the competitive environment and the strategy of a firm. The significance of Parsons work was that it shifted the perspective away from technology to a firms strategy. McFarlan (1984) expanded this theme by noting that information technology can add value to services and to products and actually throw competitors off balance. IT can be used to build up entry and exit barriers. The significance in Mac Farlans work is notion of using information technology and information in searching for possibilities. Knowledge about information assets and opportunities is important. Wiseman (1985) observes that information technology has made the market more turbulent concerning products, customers, competitors, suppliers and production methods. Wiseman further notes that an understanding of the turbulence in the organizations competitive environment is essential. McFarlan (1984), Benjamin et al (1984), Wiseman (1985) and Magee (1985) have however focused too much upon information technology itself and the distinct elements of information and technology are confused, and in which information technology frequently appears as a conscious and unconscious synonym for information. It might be a seriously misleading understanding that allows stress to be placed upon enabling mechanisms to the detriment of serious considerations of content and purpose aspects of information behaviour.

In Porter and Millars work (1985) information technology is conceived even more broadly as information that a business creates and uses as well as the wide spectrum of increasingly convergent technologies that process this information. Machlup(1962) very carefully observed that very economical activity has both a physical and an informational component. Machlup found that the adding of value is given by the informational component. Porter (1979) noted in the same way that information and processing associated with a value activity have many unexplored opportunities for advantage - sometimes even being sold as a separate product.

Technological opportunities available in the marketplace to all competitors in an industry (personal computers, software, third party communication lines etc.) may permit short term strategic gains or catch up moves. But to achieve defensible, long term strategic benefits, those external opportunities will probably 
have to be linked to unique assets currently among the organizations resources, and, most likely, to the organizations distinctive competences, or the factors that give that give it an advantage over it competitors. That is, pure information technology offers little strategic advantage, advantage flows from using technology to leverage or exploit inimitable assets of the company - its history, reputation, culture, management skills, market power (Barney 1983). This is linked to communication skills and the management of the information flow in the company. This include the ability to translate diagnostic results into specific and knowledgeable information requests. The satisfaction of the latter, within acceptable time, cost and human ability constraints requires the establishment of external and internal information systems associated with the active handling of information as a management resource of comparable importance to other factors of production.

A number of journal articles reported on cases of competitive advantages and a number of academic articles were published (Ives and Learmonth 1984, Benjamin et al 1984, McFarlan 1984, Scott Morton 1989, Rockart and Short 1984, Cash and Konsynski 1985, Porter and Millar 1985). In Britain contributions appeared from King (1986), Earl (1987), Feeny (1987) and others. Extensive treatment of the economic consequence of information systems appeared in Strassmann (1985) and a large number of case studies of Strategic Information Systems (SIS) were reported in Wiseman (1985), while the competitive use of telecommunication came on the agenda in Keen (1986) and Clemons and McFarlan (1986) and Methlie et al (1986).

This is not to say, however, that all strategic systems provide an organization with an advantage. As Clemens and Kimbrough (1987) argue an system can be strategically important for different reasons - it can be a source of competitive advantage or it can be a strategic necessity, necessary for the business but widely available in the industry. Furthermore, they believe in an evolutionary theory of strategic development whereby ultimately all strategic systems become strategic necessities.

This expanding role of information technology in business has forced strategic information system planners to change the scope, objectives, style and sources of expertise in planning ( Sullivan 1985, 1988). As a consequence, strategic information resource planning has been argued to be the single most important information management issue for the 1990s (Earl 1983, Dickson et al 1984, Brancheau and Wetherbe 1987, Galliers 1987, Zeleny 1989).

Porters focus on information and how it can be used constructively to advantage is an important contribution in this direction. Not only does it shift the major interest away from technology itself, but it ties the thrust back to original decision making themes. It is of course, the information provided by technology that is important rather than the technology itself.

In one company it might be the information technology and not the information itself that is the key factor in achieving competitive advantage or a 
product differentiation. For example, firm A determined that relations with its customers could be strengthen by placing terminals in each customer location to allow for easier order placement as well as providing a means of advance price and availability checking. However in another company it might be the information itself rather than information technology, that is the key resource to strengthen their competitive position. The primary distinction between these two approaches lies in the source of the value added. In the first example, the introduction of technology increased the value of existing information by for instance providing easier access or speeding up the transfer time. Over time might however the information about their customer base be more important than the information technology. In the second, the information itself provides a strategic advantage through the new uses to which it is put or through better flow of information.

There is therefore the need to distinguish between two varieties of information resources - information technology and information. Information technology can be defined as the hardware and software that is used to collect, transmit, process, and disseminate symbols in an organization. Information is external and internal data that have been evaluated for different form of uses. There are a variety of levels of information : for example, those data that have been evaluated for and thereby incorporated into, a database, those data that have been further evaluated to memos to managers, or further on to the top managers. There is a value chain in the evaluation process from data to information to knowledge.

In some cases will the strategic uses of information technology and information be very interdependent. The companies will in these cases be using both information technology and information to gain competitive advantage. For instance Scandinavian Airlines are using both information technology (the widely distributed terminals) and information (supply-demand data for various routes and prices) as ways of gaining strategic advantage. For American Express the information technology is necessary to provide information about their customer which is used for service differentiation and for the evaluation of which companies they can cooperate with to offer complementary services.

Strassmann (1985), Machlup (1962) and Olaisen (1989) concluded all with that information is tangible and hard to assess or measure. The literature on the "value of information" is vast, but no single agreement on measure exist of information value. Since it is difficult to measure it might be pushed in the background, even if the potential to produce benefits might be better for information than for information technology.

The important question is: How can organizations discover appropriate strategic opportunities, some of them involving the use of information technology, some involving the use of internal and external information as a strategic resource and some involving both information technology and information as a strategic resource?

Moving from celebrating the opportunities to investigating the circumstances 
and conditions for information and information technology to be used strategically, the research to be carried out in the future should search for competitive advantages in four different ways according to Earl (1987):

to gain competitive advantage

to improve productivity and performance

to enable new ways of managing and organizing

to develop new business

Earls four categories reflect the revolution in the conception of strategic information systems (IS), since by then the scope for changing competitive structures and strategies had been on the agenda of corporate management for some time. As Earl remarks (1987:158): "A new research area thus has arrived, potentially combining at least the bodies of knowledge about information systems, business strategy, organizational behavior, information resources management and industrial economics".

\section{IRM AS A PART OF THE OVERALL BUSINESS STRATEGY}

Let us first present a model for business planning where external and internal know-how management is included. The first we need is a vision of where we want to go (i.e. the business idea). Second we need a strategy described as the means to achieved the vision. Then we need the strategy broken down from the macro level to strategic goals on the micro level. To be able to brake the goals down we need to have knowledge about the critical success factors for our company. These might be broken down to our critical decision sets, our value-based processes and our critical assumption sets. These factors are agin dependent on our definition of our information needs and our information policy which make up our analysis of our internal and external information resources situation. The management of internal and external information decide especially upon our critical assumption sets, but also upon our value based processes and our critical decision sets. Information Resources Management decides upon what areas we are apply information technology and the flow of information in our business. It is however our business model which is crucial for our information policy and for what IRM services we need.

Information Resources Management is the integrated management of both information(internal and external) and information technology applied to areas corresponding with the strategy and the critical competition factors of an organization. IRM is the synthesis of a range of ideas based on the premise that 
effective decision-making and strategic thinking cannot be divorced from information consideration. The satisfaction of the latter, within acceptable time, cost and human ability constrains requires the establishment of external and internal information systems associated with the active handling of information as a management resource of comparable importance to other factors of production. IRM has to be integrated in the overall strategy of a company.

Our proposal for a Strategic Methodology for Information and Information Technology:

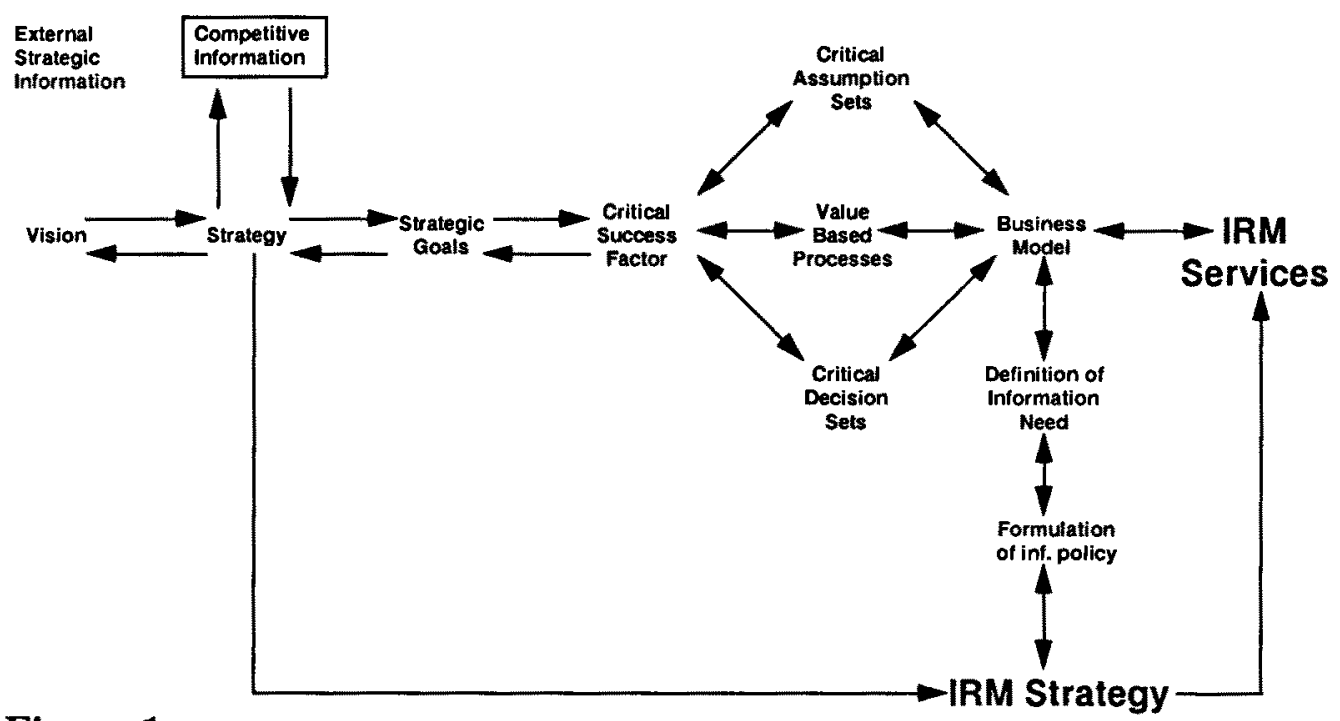

Figure 1

Irm as a Part of the Business Strategy

The new forms of organizations demand also more internal and external information than the traditional hierarchical organizations. What does a dynamic network look like? It might be a piece of furniture designed by IKEA in Sweden, engineered in Germany to meet the requirements of the large single market in 1992, manufactured in Korea and the Soviet Union, distributed through a multinational market network with initial distribution from Belgium. Similarly it might be a hotel who buys their food services from one company, their cleaning services from another company, their service evaluation and design from a third company while they are connected to a car rental company and a hotel reservation system. Overall, the brokering, connecting networking role is becoming increasingly important. Whether locating suppliers, designers, producers and distributors. The frequently computer-based competence to bring people and things together quickly and efficiently is a key factor in organizational flexibility. This dynamic network organization demands a strategic management of the information flows 
from the brokers to the designers, producers, suppliers and distributors.

To understand information resources management we need to look into what kinds of information we have.

\section{WHAT KINDS OF INFORMATION DO WE HAVE ? DOCUMENTARY VERSUS NON-DOCUMENTARY INFORMATION}

A substantial part of knowledge relevant to the industrial and service enterprise is externally available on material information carriers. By documentary information is understood: All knowledge, experience, facts, opinions, know how etc., recorded in any way on paper, film, discs or by electronic means. In other words formal information that can be stored and easily retrieved. Informal information transferred verbally by gestures, by telephone, telex etc. as well as internal and nonpublished information is very difficult to systematise, store and retrieve.

Documentary information has certain advantages and disadvantages compared to other forms of information. It can be expected that documentary information can provide a more complete and objective review of relevant events. It is also less expensive than information obtained from consultants. The most important drawback of documentary information is its general character, it is often less tailored to specific user needs as compared to more informal forms of information. We have illustrated the different types of information in Figure 2.

Verbal communication offers a considerable advantage in the prime importance: It allows exchange of thoughts. Through "face-to-face" communication the elements of confidence can be reinforced, which directly responds to the need of reducing uncertainty. The feedback allows the information to be tailored to the specific need of the user.

The information disseminated by formal elements is permanently stored and, typically, retrievable; information conveyed by informal channels is often stored only temporarily and is difficult to retrieve.

According to virtually all empirical studies the informal information sources are the most important ones for all types of work. Nothing can replace the "face value" of information or the importance of informal networks or "invisible colleges". Parts of the informal information are however formalized through internal electronic archives where it may be stored and retrieved by immediate access. The Hyper-Card solutions or IBC solutions with integration of natural text searching combined with voice identification and pictures may change the way we are working with formal information. 


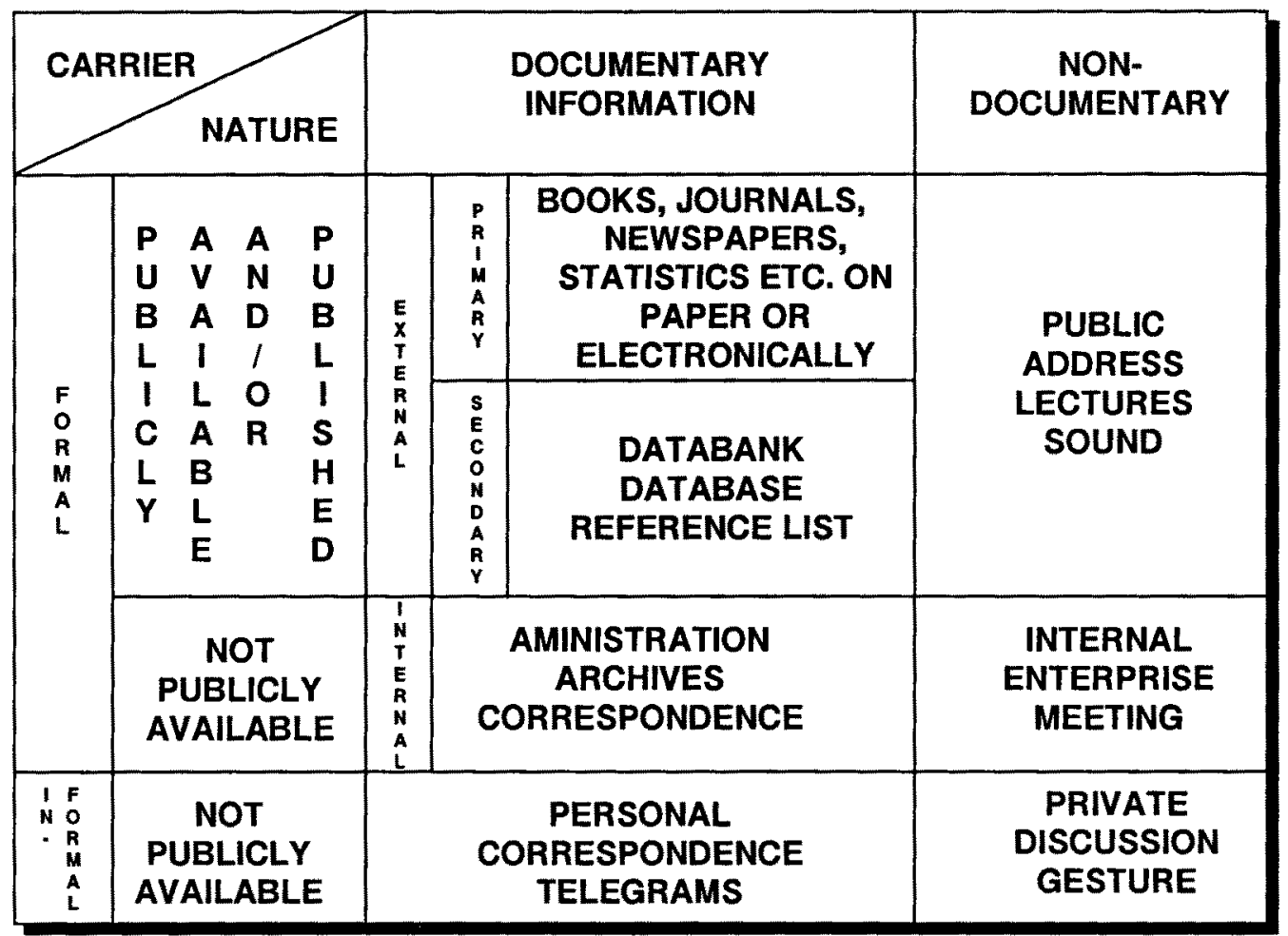

\section{Figure 2}

The Nature of Information

With this as a background us present the different types of processing service that need to be provided in a company or a consortium of companies. The user has a work station that provides access to a range of shared services. The shared services, consisting of applications and utilities. The difference between them are that applications are developed to perform specific operations on particular files of information, while utilities are general purpose, open-ended tools. The applications and utilities provide various means of recording, searching, extracting and distributing information. Beyond this layer again are the files of stored information - data, text, images, pictures, knowledge or whatever together with the logic for retrieving, identifying, and updating specific records, which I term information management.

Both information and the associated applications and utilities can be shared and located corporate, work group/departmental, or personal level. Some information additionally is stored externally to the organization. This information might also easily be used by the individual user from his personal computer.

Figure 3 is an illustration of how information is used by the individual user 


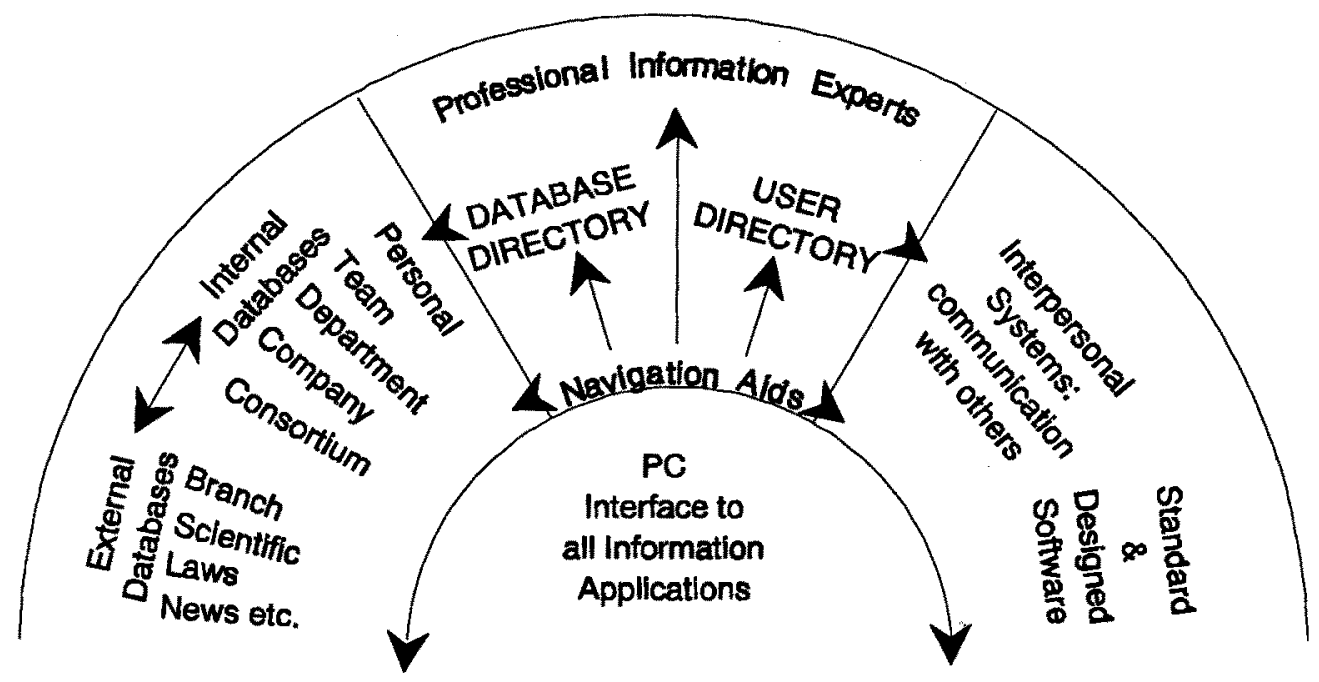

\section{Figure 3}

Electronic Information as a strategic Resource
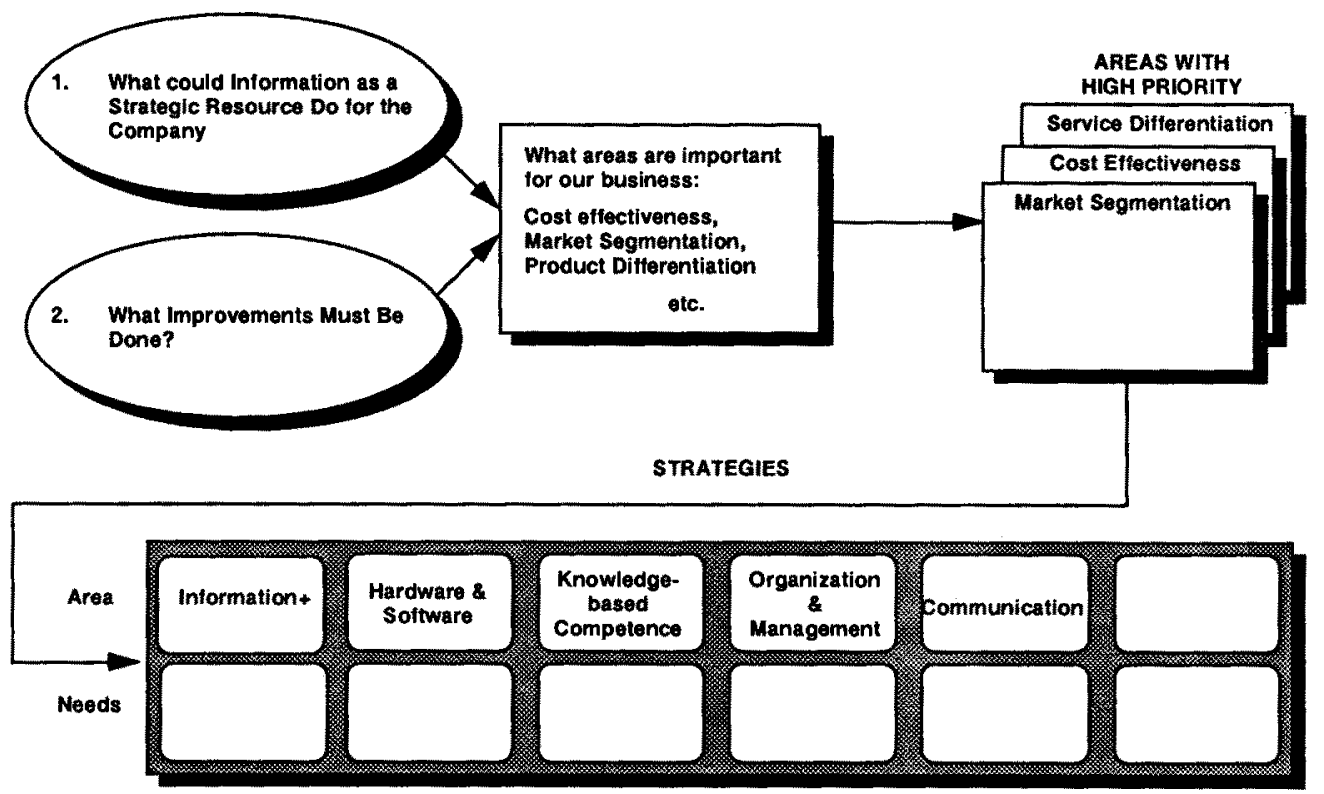

Figure 4

Formulation of the IRM Strategy 
from his personal computer (i.e. the user perspective). Information resources management is the management of:

口 internal and external information systems

- work stations with applications and peripherals

ㅁ generic applications for information access and work specific applications for information access and work

a professional information specialists providing navigation aids and information

exchange between individuals and groups.

Figure 3 gives a perspective of the possibilities that for instance is already available for the researchers in the Norwegian company : Hafslund Nycomed.

What all companies must evaluate, is what kind of information infrastructure each individual needs from his P.C. This is, as showed in Figure 1, dependent on their business model. They have to ask about, what their information, as a strategic resource, can do for us - and in what business areas it can be applied. This is illustrated in Figure 4.

Let us then look into how business organizations in Norway are actually using internal and external information. This is based upon our own empirical research in Norwegian companies (Olaisen 1989, 1990, 1991).

\section{CLASSIFICATION OF EMPIRICAL FINDINGS: INFORMATION AS A STRATEGIC RESOURCE}

\section{Hypothesis}

The companies which have a high use of external information and at the same time have a high degree of information technology investment will have the highest potential for profit in their system because high use of external information give a higher degree of flexibility in turbulent environments and that IT investments give competitive advantages.

A high degree of IT investments is the staffs own perception of how much the company has invested in information systems. The use of external information is measured against the following activities:

1. Cost competitiveness (i.e. organizational effectiveness)

2. Customer services 
3. Supplier relations

4. Cooperation/Consortium possibilities

5. Product differentiation

6. Service differentiation

7. New product planning

8. New service Planning

9. Market segmentation

10. Financial information.

The companies where this research models have been used include 40 Norwegian hotels together with 83 Norwegian banks, financial institutions and insurance companies. The research methods include in depth interviews with the managers and a postal questionnaire sent to a representative sample of the employees. In the hotels the postal questionnaire was sent to 500 employees with a responserate of $68 \%$ while the postal questionnaire was sent to 500 employees in the banks and insurance companies with a responserate of $72 \%$.

The reason for choosing hotels and banks was that many of these organizations in Norway have been into a deep financial crisis. It was then easy to find a representative sample with organizations in different life phases.

The aim of the research has been to investigate the success and profitability of the companies versus their use of information technology and external information. The aim is to get a picture of to what degree information is a strategi resource and in what organizationsal life phase information technology and information is most important for an organization.

\section{INFORMATION AS A STRATEGIC RESOURCE IN HOTELS}

We have found that the hotels which have high investments in IT together with a high use of external information are more profitable than the other hotels. We have named these hotels creative hotels. They are using the technology to create new business opportunities and to become more cost effective. The management of their customer base is central for these hotels.

The hotels which have high use of external information, but a low investment in IT might be called solid systems. They will have great difficulties in getting the same competitive advantages as the creative hotels. These hotels are market oriented in the way that they know very much of what is going on in the market.

The hotels which have invested much in IT, but have a low degree of use of external information might be called risk systems. These hotels will have a low 
EXTERNAL INFORMATION

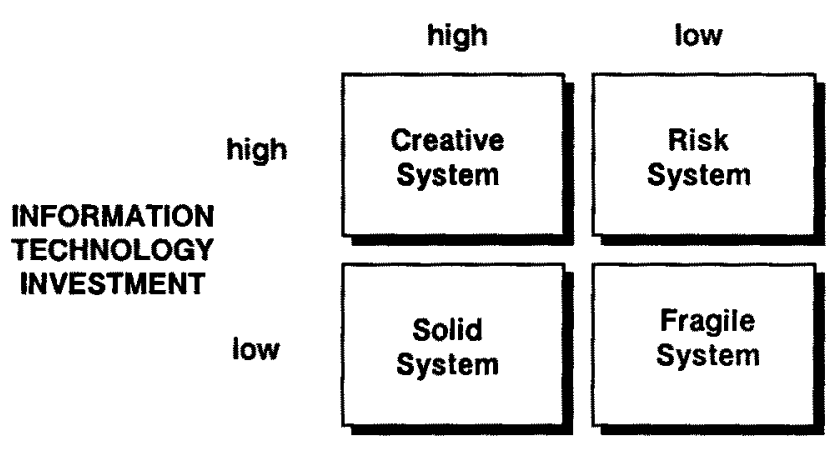

\section{Figure 5}

potential for using their investment. This is the hotel with advanced information systems, where the staff is not trained to use the system, and the hotel is anyhow operated as before.

The hotels which have neither invested in information technology nor have invested energy in a high degree of external information are fragile systems. This is the old traditional hotel, which is not hooked up in an information system where the family management is doing what they often have been doing for generations.

The results correspond with the results indicated in Johannesens doctor dissertation (1990).

This illustrated in Figure 5.

Like Ginman (1987) found in Finland the results also indicate that the companies might be divided into four stages :

I. The hotel is in its intial phase. The risk is high and the feedback on the investments is slow. The products are still a question mark. The hotel is very interested in marketing and to get the service delivery system to work. The hotel is unsure about which market segments it wants to concentrate on.

The interest in external information is often high, but the investments in IT technology is low.

The ideas are mainly coming from internal sources and these hotels have very small needs for documentary information and formal information.

II. The hotel is in a revival phase. The spirit is high and the hotel has a better strategy, a clearer definition its market segment and what service level it wants to offer. The service delivery system is redesigned and the hotel has invested in information technology and is very interested in external information especially about market segmentation and product differentiation/profitability.

A typical feature in this phase is great interest in innovation and change. A 
great deal of time is put into developing and maintaining effective communication with the outside world.

The hotels are using bother internal and external information for their idea generation/innovations and the need for documentary external information is increasing.

III. The hotel is in a maturity phase where the hotel has invested in information technology and is trained to use the technology to milk the same cows as before. The company has a low interest in using a lot of time on keeping up with external information about the products, product differentiation and market segmentation. It is business as usual.

The hotels are using internal sources for their idea generation/innovations and have low needs for external documentary information.

IV. The hotels are in a crises situation. It seems like the organizational learning is low and the interest for what is going on the market is slowing down. The hotels in this category is often looking for financial reconstruction or alliance partners. Theses hotels have passed into an information hostile phase.

The hotels have a low degree of innovation and are not using external information to any degree.

The results are illustrated in Figure 6.

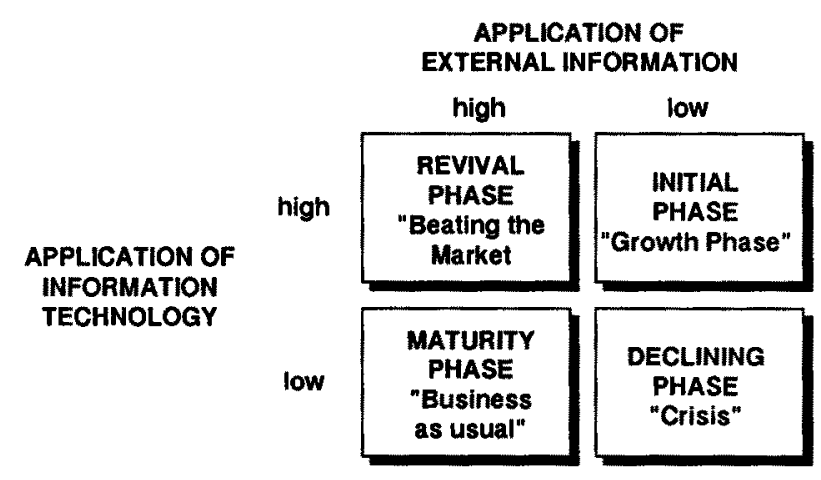

Figure 6

We also investigated those hotels which had been into a turbulence $(\mathrm{N}=16)$. It seemed like they went into three phases: One where the crisis continued $(\mathrm{N}=5)$, one where the development continued in bumpers $(\mathrm{N}=8)$ and one where the growth continued $(\mathrm{N}=3)$. Three important patterns were found for these who continued to grow: They became more cost effective, they increased the use of their customer base and they went into partnerships with other hotels. The "ups and downs" also increased their use of their customer base and their marketing effort 


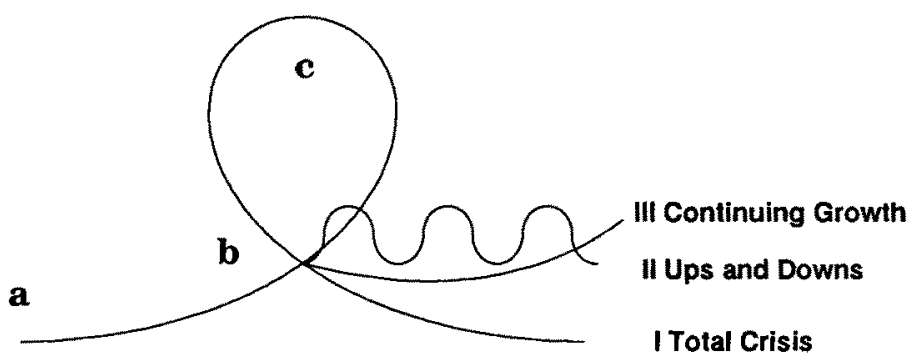

\section{Figure 7}

After the turbulence

- and those in total crises never decided quite what to do. They had either no choice (the financial burden too heavy) or they could not decide upon a consistent strategy.

We also investigated if the IRM concept had reached these hotels. None of them had heard about it. Explained to them it was not looked upon as strategic important of the following reasons :

1. Low perceived importance of the IRM concept .

2. Difficulty in assessing tangible contribution

3. Other priorities are more important

4. Budgetary constraints.

5. Complexity of the concept to high.

6. Lack of appropriate technical staff to implement the concept.

The results were similar in the banks and insurance companies with a stronger emphasis on the difficulty in assessing tangible contributions from IRM.

\section{COMPARISON OF THE RESULTS}

We investigated the Norwegian banks and insurance companies and divided them into the following group of companies :

1. Maturity companies, This is companies which have not been into a crisis bit have had a rather steadily growth period. Examples of such companies are "Forenede Forsikring" and "Nordlandsbanken".

2. Nichestarters. This is companies which have started some years ago and concentrated on a niche in the market. Examples are "Aktiv", "David", "Liv-Nor", "Oslobanken". These companies must be classified as medium sized companies. 
3. Revivers. This is companies which have been into a reorientation and are getting out of this with strategy adjusts or reorientations. Examples are "Kreditkassen" and "Gjensidige Forsikring".

4. Crises companies. This is companies which are into a crises and are concentrating upon solving their immediate problems. Examples are "Sunnmrsbanken","Fokus", "Sparebanken Nordland" and "Vesta-Hygea".

The classification was used to compare the companies investment in information technology versus use of information. We will see from figure 8 that the differences are found for revivers and nichestarters. The revivers among the hotela had high investments both in information and information technology while the revivers among the banks only had high investments in information as a resource. The reason for this migh be that the banks for many years had invested in information technology without any results and thay they now were mainly interested in information about their customers to use it in their credit management to decrease their losses. The other difference was for the nichestarters which among the banks and insurance companies had high investments both in information and information technology while the hotels in the same phase only had high investments in information systems. The reason for this is that the complexity of the organizations are different. The hotel managers in this phase needed information systems to be a part of the market, but had the information about the market "intheir heads". For the nichestarters among the insurance companies the information systems were crucial to be able to handle the business, but still the information about the customers for segmentation and marketing were looked upon as essential for the business. The results for the banks are illustrated in figure 8.

The conclusion seems to be that there might be more similarities in what phase a company is in than the actual size of it concerning the need for external information and also to some degree concerning the need for investment in information technology.

We have for all the companies looked into two research questions :

1. What are the alternative change strategies for these companies?

2. For those companies with high investments in both information technology and external information how is the time and effort schedule for changing the company into a knowledge based company?

For the first question there seemed to be four patterns : 


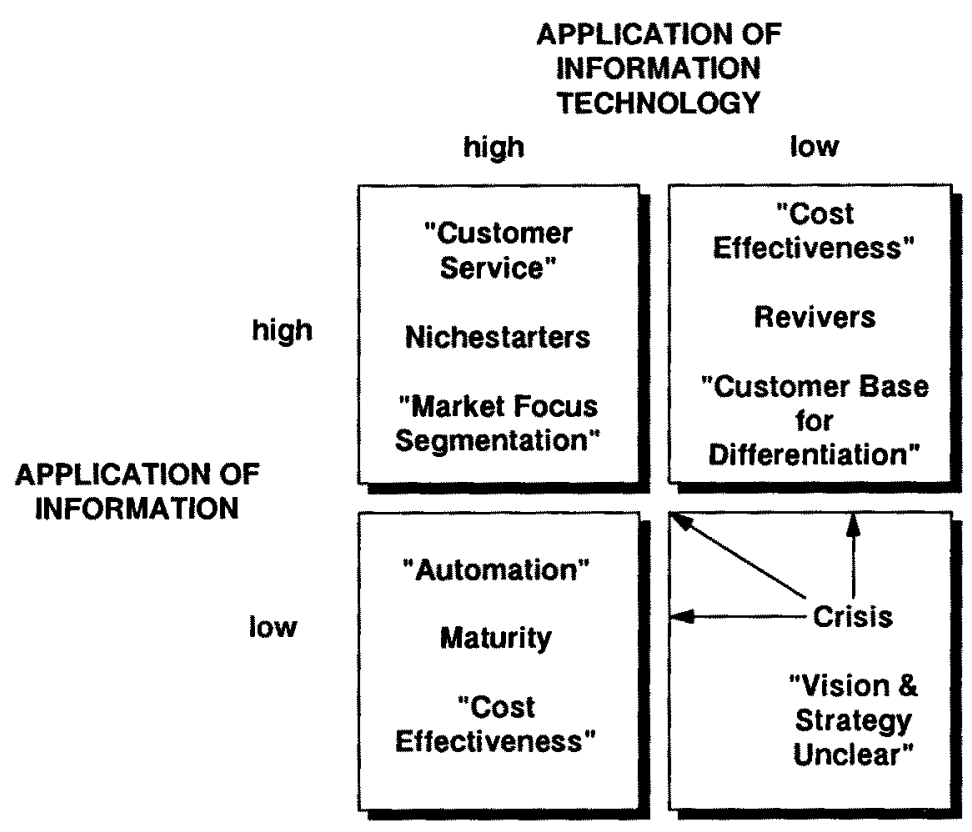

Figure 8

Application of Information \& Information Technology

1. The companies ignoring both the long term information resource development and the short term business demands went into a crisis.

2. The companies with the long term information resource development incorporated but the short term business demands ignored went into a programmatic change.

3. The companies ignoring the long term information resource development but incorporating the short term business demands all went for cost reductions. When the crisis increased they went for more cost reductions.

4. The companies incorporating the long term information resources development and the short term business demands went for a critical knowledge based path.

The companies on the knowledge based path were transformed from being information and data based companies to become truly knowledge based companies. It seemed like these companies $(\mathrm{N}=8)$ went though a transformation in four stages:

1. The first stage in their evolution might be said to be based upon information resources management. An example of this is the insurance company Liv- 


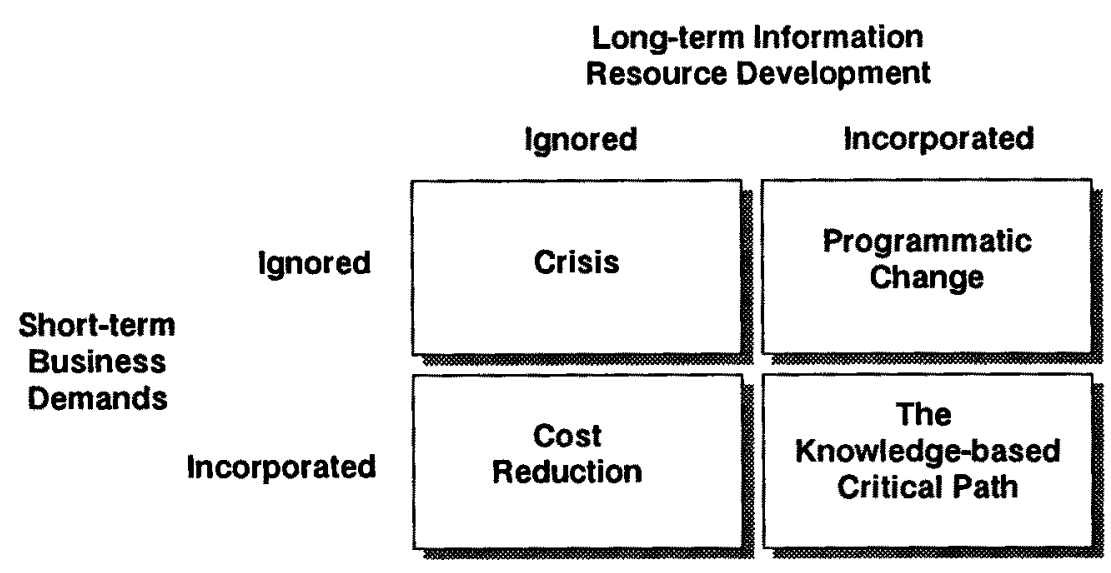

\section{Figure 9}

Alternative Change Strategies

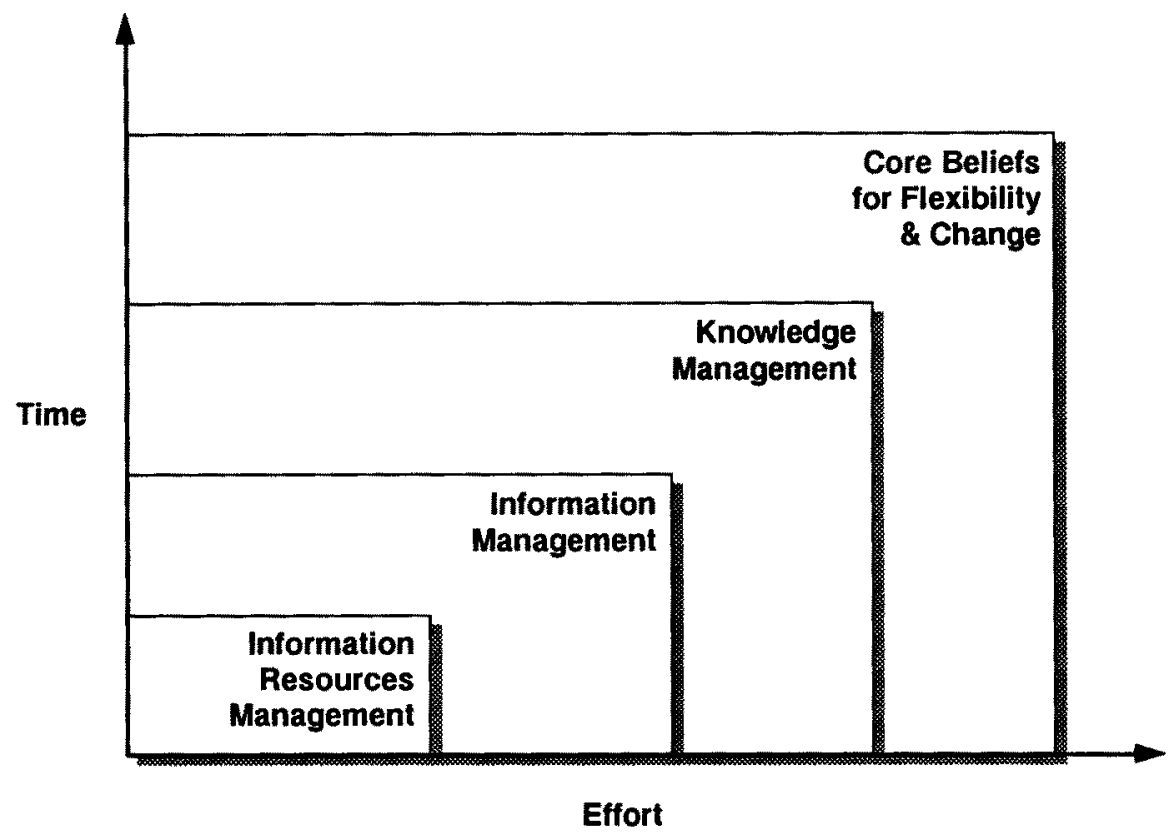

Figure 10

Changing Information Culture: Time and Effort 
Nor where information about certain groups of people is the basis

2. The second stage might be said be built upon information management. An example of this is the insurance company David where the information and not the technology is essential.

3. The third stage might be said to be based upon knowledge management. An example of this is the insurance company Aktiv where the knowledge about the profit about certain customer segments is the bread and butter for the company.

4. The fourth phase is the company where the information is transferred to knowledge in the employees and where the employees see this as a possibility for changing the service concepts.

This is illustrated in Figure 11.

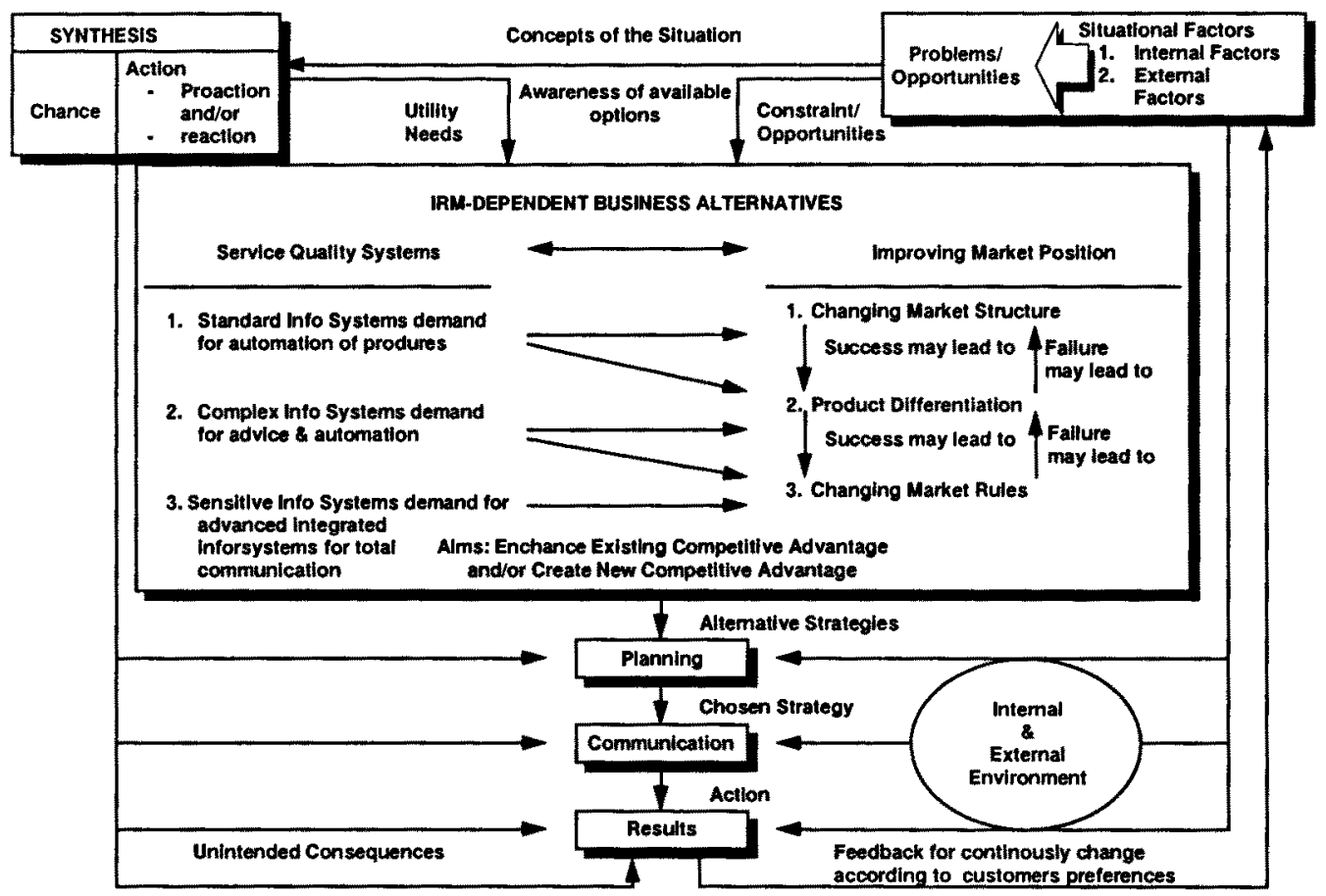

Figure 11

The Process of Using Information as a Strategic Resource

This give further the evolution of three different strategic information systems: 
1. A standard information system where current procedures are automated.

2. A complex information system where the system is integrated to give the employees advice about what to do and what to take action upon.

3. A sensitive information system where the total communication is possible

\section{A FRAMEWORK FOR INFORMATION RESOURCES MANAGEMENT}

The proposed framework consists of five elements:

The concept of a SYNTHESIS for the process of gaining competitive advantage through information technology, being a motivationally-neutral term, allows for the role of chance in determining the starting point of such a process where we either take deliberate action or we involve a degree of chance. The action involve either a proaction (i.e. being an innovator) or a reaction (i.e. being a follower). The action result in wants and needs (i.e. a defined strategy). On the other side the problems and opportunities from the prevailing internal and external factors (i.e. the Situational Factors) will decide upon how we define the situation and upon our awareness. The three level of information systems are defined into the model.

The Synthesis and the Situational Factors leads to a choice among a number of IRM dependent Business Strategy Alternatives. Our aims will be either to enhance existing competitive advantage (i.e. improve the information resources management by build an information culture) or to created new competitive advantage (i.e improve our market position (i.e. changing the market rules by an innovation or propose a service/product differentiation. The synthesis, the Situational Factors and the IRM dependent Business Strategy Alternatives will affect the Planning and the Communication. The possible results are identified earlier in this study :

1. Cost competitiveness (i.e. organizational effectiveness)

2. Customer services

3. Supplier relations

4. Cooperation/Consortium possibilities

5. Product differentiation

6. Service differentiation

7. New product planning

8. New service Planning

9. Market segmentation 
These outcomes will have effect upon the situational factors and decide upon the possibilities for information resources management.

The option chosen has been cost competitiveness (i.e. automation of current practice). It looks like this strategy has not given the desired organizational effectiveness and most of all not new business strategies.

The other option is the integration of information technology into the organization. It seems like this is essential for improved customer services and supplier relations. This is the option chosen by the mentioned maturity and niche companies for the 1990s.

The third option is building a sensitive information culture. This seems to be necessary to be able to differentiate services and products through market segmentation. A prerequisite for such an option is that the transactions already are automated and the aim now is to get an optimal use of internal and external information. The core task of such an organization is information processing moving information among individuals and groups in order to coordinate work. The basic structure for coordinating information processing traditionally has been hierarchy. Hierarchical organizations were built by grouping jobs/roles into work units and linking these via common reporting relationships and successive levels of management control. Perhaps the greatest single influence on organizational architecture has been the evolution of information technology. By providing alternatives to hiearchy, information technology is revolutionizing organizational design. Information systems, common architectures, shared data bases, decision support tools and expert systems - all create the capacity to coordinate behavior without hierarchical control. Such technology allows the creation of autonomous work units, linked together by information. It also allows looser coupling, without sacrificing the capability to coordinate and oversee.

The great potential of information technology - combined with the great demands of ever-changing competitive environment- has led to innovations in organization design. This innovation might be found in the dynamic learning organization based upon an information culture.

This is the organization willing to learn from the customers and the competitors. This is the organization where information is the strategic raw material for action in the design, production and delivery of services and products. This is the organization backing three fundamental initiatives :

- Creation of competitive advantage from information about customers and markets (competitors).

- Definition of internal and external information needs

- Creation of new measures of performance for information services.

This learning has to work in the way that each worker has an understanding of the design, production and delivery of the services and products. The 


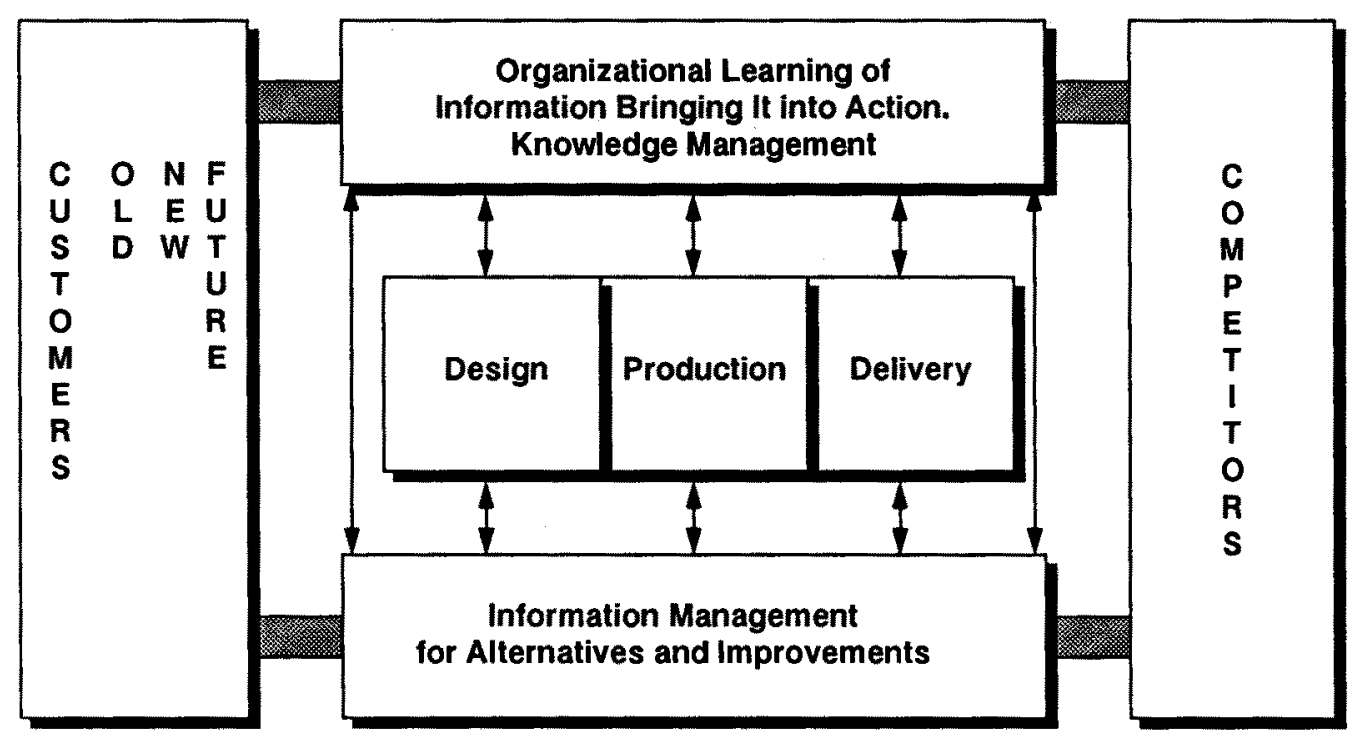

Figure 12

The Dynamic Learning Knowledge Organization

understanding of the whole concept is necessary to be able to have suggestion about improvements. The improvements might be incermental, but the information from the markets and the customers give a possibility to improve the parts of the production chain where the quality is inferior or starts to be inferior. The rwaw materila for the dynamic learning organization is information.

This organization is roughly illustrated in Figure 12.

\section{CONCLUSION}

The theory of information technology as a strategic weapon has changed in the way that the management of internal and external information as a resource itself is looked upon as important as the management of information technology.

One of the ironies of the information revolution is that so few of those involved can give any definition of what information is. Starting point for most who would try to do that is still the theory of information published in 1948 by Claude Shannon in the Bell Systems Technical Journal. Information, argued Claude Shannon, reduces uncertainty. If a piece of data convinces you of something you had previously thought very unlikely, then there is a Great deal of information 
in it. If it merely tells you what you already know, then there is no information.

Shannon built from this insight a detailed mathematical definition of information. Though his intent was to quantify the information-carrying capacity of telephone lines, his theory can also describe most computers. Most of what computers do is to reduce uncertainty in one way or another. As number crunchers they can distill answers from data about sales or inventory levels; as databases they can store complete libraries of information, enhanced with the technology of expert systems they can dispense scarce human expertise to whoever needs it; and as communicators they can send the information they hold across the world.

This does not mean that computers - however advanced they may be - can work with information in anything like the way people do. The distinction between peoples information-handling skills and those of machines will largely determine which of todays human activities are duplicated by machines - and thus devalued. Many is the company which churns out similar products or services year after year, doing the same business in the same way. Information technology will make such firms increasingly easy to copy - when copying is worth while. But it may also make it easier for groups and teams to learn new tricks.

The technology can show all workers the same overview of the company - so that they can see why this year the emphasis should be on, say, customer quality while last year it was on quality in manufacturing. The technology can show each worker, day-to-day, month-to-month how his actions affect the team and the organization. And it can broadcast his bright ideas to the company as a whole.

Building such learning organizations is vast challenge. It requires new skills, clever people and capable machines. It requires both high standards and a commitment to keep learning. The ability to learn as a team will become increasingly important from companies looking to avoid being dragged down by hordes of copycat competitors. Learning from and with fellows workers helps to keep a step ahead of the competitors. Helping customers to learn can inspire them to keep buying your products and services. Learning from customers helps to pay attention to their changing needs. The dynamic learning organization is the essence of using information as a strategic resource. 


\section{References}

Benjamin, R.I., Rockart, J.F.,J.F. Morton,M.S.S. and Wyman, J. 1984. Information Technology as a Strategic Opportunity. Sloan Management Review (Spring): 3 10.

Barney, J. B. 1983. Strategy and Organization. Working Paper. Los Angeles, UCLA Graduate School of Management

Barry, J. B. 1983. Strategy and Organization. Los Angeles : School of Management, UCLA.

Bell, D. 1973. The Coming of Post Industrial Society. New York: Harper\& Row.

Brancheau, J.C. and Wetherbe, J.C. 1987. Key Issues in Information Management. MIS Quaterly 11 (1): 35-45.

Cash, J. and Konsynski, B. R. 1985. IS Redraws Competitive Boundaries. Harvard Business Review (March-April): 134-143.

Clemens, E.K. and Kimbrough, S.O. 1987. Information Systems and Business Strategy. WP 87-01-04. University of Pennsylvania, Wharton School.

Dickson, G.W.; Leitheiser, R.L.; Wetherbe,J.C and Nechis, M. 1984. Key Information Systems Issues for the 1980s. MIS Quaterly 8 (3): 11-17.

Earl, M. J. 1983. Emerging Trends in the Management of New Technologies. In: Piercy, N. (ed.). The Managment Implications of New Information Technologies.Croon Helm.

Earl, M. J. 1987. Information Systems Strategy Formulation. In: Critical Issues in Information Systems Research. R.J. Boland and R.A. Hirschheim (eds.) John Wiley.

Feeny, D. 1988. Creating and Sustaining Competitive Advantage. In: Information Managment. M. J. Earl (ed.). Claredon Press.

Galliers, R. D. 1987. Information Systems and Technology Planning in a Competitive Strategy Framework. In: Griffiths, P. (ed.). Information Managment. Pergamon Press Infotech.

Ginman, M. 1987. De Intellektuella Resurs-Transformationerna.Åbo Akademis Frlag.

Ives, B. and Learmonth, G. 1984. The Information System as a Competitive Weapon. In: Communication of the ACM, vol. 27, no. 12 (December): 212-231.

Johannesen, J. A. 1990. Organisatorisk Systemutvikling og Informasjonsledelse. Akademisk avhandling fr filosfie doktorsexamen. Stockholm Universitet.

Keen, P.G.W. 1986 . Competing in Time. Ballinger.

King, W.R. 1986. Developing Strategic Business Advantage from Information Technology. In: Piercy, N. (ed.). The Managment Implications of New Information Technologies.Croon Helm.

Laudon, K.C. 1988. Managment Information Systems : A Comteporary Perspective. New York: Mac Millan.

Lucas, H. C. and J. A. Turner. 1982. A Corporate Strategy for the Control of Information Processing. Sloan Management Review 24(3): 25-36.

Machlup, F. 1962. The Production and Distribution of Knowledge in the United States. Princeton University Press.

Magee, J. F. 1985. What Information Technology has in Store for Managers. Sloan Management Review (Winter): 45-49.

McFarlan, F. W. 1984. Information Technology Changes the Way you compete. Harvard Busisness Review (May-June): 98-103. Methlie, L. B. 1986. Informasjonsteknologi - en Strategisk Utfordring.

Mintzberg, H. 1987. Crafting Strategy. Harvard Business Review (July-August):6675.

Olaisen, J. 1984. Toward a Theory of Information Seeking Behavior Among Scientists and Scholars. Ph. D. dissertation. University of California, Berkeley.

Olaisen, J, 1989. Pricing Strategies for Library and Information Services Libri 39 (4) : $25 \dot{3}-274$.

Olaisen, J. , Olsen, G. and Revang. 1990. Bridges and Tunnels. Strategic Alliances and the Use of Information as a Component in SASs Strategy. Oslo: The Norwegian School of Management WP 1990/34 and WP 1990/45.

Olaisen. J. 1990. Information Versus Information Technology as a Strategic 
Resource. International Journal of Information Management (10): 192-214.

Olaisen, J. 1991. Information as a Critical Success Factor in Small and Medium Sized Enterprises. The Norwegian School of management WP 1991/12.

Parson, G. L. 1983. Information Technology: A New Competitive Weapon. Sloan Managment Review 25(1):3-14.

Porat, M. 1977. The Informtion Economy. Palo Alto Stanford University.

Porter, M.E. 1979. How Competitive Forces Shapes Strategy. Harvard Businsess Review (march-April): 137-147.

Porter, M. E. and V. E. Millar. 1985. How Information give you Competive Advantages. Harvard Business Review(July-August):149-160.

Rockart, J. F. and Short, J. S. 1984. Information Technology and the New Organization. Sloan Management School WP \# 2076-88.

Scott Morton, M.S. 1989. The Impact of Information Technology on Organizations in the $1990 \mathrm{~s}$. Siemens Review (3):5-9.

Starbuck, W.H. 1983. Organizations as Action Generators. American Sociological Review, 48.

Strassmann, P. 1985. The Information Pay-Off. New York:Free Press.

Wiseman, C. 1985 . Strategy and Computers: Information Systems as Competitive Weapons. Homewood(ML): Dow Jones-Irwin.

Wiseman, C. and MacMillan, I. C. 1984. Creating Competitive Weapon from Information Systems. Journal of Business Strategy, 5 (no. 2): 42-49. 